\title{
Correlations between disease-specific and generic health status questionnaires in patients with advanced COPD: a one-year observational study
}

Sarah Wilke ${ }^{1 *}$, Daisy JA Janssen ${ }^{1,2,3}$, Emiel FM Wouters ${ }^{1,4}$, Jos MGA Schols ${ }^{5}$, Frits ME Franssen ${ }^{1}$ and Martijn A Spruit ${ }^{1}$

\begin{abstract}
Background: Longitudinal studies analyzing the correlations between disease-specific and generic health status questionnaires at different time points in patients with advanced COPD are lacking. The aim of this study was to determine whether and to what extent a disease-specific health status questionnaire (Saint George's Respiratory Questionnaire, SGRQ) correlates with generic health status questionnaires (EuroQol-5-Dimensions, EQ-5D; Assessment of Quality of Life instrument, AQoL; Medical Outcomes Study 36-Item Short-Form Health Survey, SF-36) at four different time points in patients with advanced COPD; and to determine the correlation between the changes in these questionnaires during one-year follow-up.

Methods: Demographic and clinical characteristics were assessed in 105 outpatients with advanced COPD at baseline. Disease-specific health status (SGRQ) and generic health status (EQ-5D, AQoL, SF-36) were assessed at baseline, four, eight, and 12 months. Correlations were determined between SGRQ and EQ-5D, AQoL, and SF-36 scores and changes in these scores. Agreement in direction of change was assessed.
\end{abstract}

Results: Eighty-four patients (80\%) completed one-year follow-up and were included for analysis. SGRQ total score and EQ-5D index score, AQoL total score and SF-36 Physical Component Summary measure (SF-36 PCS) score were moderately to strongly correlated. The correlation of the changes between the SGRQ total score and EQ-5D index score, AQoL total score, SF-36 PCS, and SF-36 Mental Component Summary measure (SF-36 MCS) score were weak or absent. The direction of changes in SGRQ total scores agreed slightly with the direction of changes in EQ-5D index score, AQoL total score, and SF-36 PCS score.

Conclusions: At four, eight and 12 months after baseline, SGRQ total scores and EQ-5D index scores, AQoL total scores and SF-36 PCS scores were moderately to strongly correlated, while SGRQ total scores were weakly correlated with SF-36 MCS scores. The correlations between changes over time were weak or even absent. Disease-specific health status questionnaires and generic health status questionnaires should be used together to gain complete insight in health status and changes in health status over time in patients with advanced COPD.

Keywords: Chronic obstructive pulmonary disease, Health-related quality of life, St. George's Respiratory Questionnaire, Health status, Disease-specific health status, Generic health status

\footnotetext{
* Correspondence: sarahwilke@ciro-horn.nl

${ }^{1}$ Program Development Centre, CIRO+, centre of expertise for chronic organ failure, Hornerheide 1, Horn, NM 6085, The Netherlands

Full list of author information is available at the end of the article
} 


\section{Background}

Chronic obstructive pulmonary disease (COPD) is a highly prevalent chronic disease, characterized by expiratory airflow limitation, which is not fully reversible and usually progressive [1]. The Global initiative for chronic Obstructive Lung Disease (GOLD) classified the severity of COPD in mild (stage I), moderate (stage II), severe (stage III), or very severe (stage IV) according to the severity of airway obstruction and the presence of respiratory failure [1]. Despite optimal medical treatment, patients experience symptoms such as dyspnea, fatigue, and/or chronic cough [2]. Consequently, patients have a poor exercise capacity and limited performance in daily life activities $[3,4]$.

Health status can be defined as "the impact of health on a person's ability to perform and derive fulfillment from the activities of daily life" [5]. A patient's selfreported health status thus includes health-related quality of life and functional status [5]. Patients suffering from COPD in all GOLD stages report an impaired health status, with worst scores reported by GOLD stage IV patients [6-8]. Therefore, improvement of health status is an important component in COPD management, including pulmonary rehabilitation [9-12].

A careful assessment of patient's health status is necessary to identify targets for (non-) pharmacological interventions, as well as to evaluate the effects of these interventions [13]. Disease-specific health status questionnaires (i.e., related to a specific condition or group) or generic health status questionnaires (i.e., intended for general use, irrespective of the underlying disease) can be used as instruments to assess health status [14]. For instance, the Saint George's Respiratory Questionnaire (SGRQ) is a commonly used instrument measuring disease-specific health status among patients with COPD [15-20], while the European Quality of Life-5 dimensions (EQ-5D) $[18,19,21]$, Assessment of Quality of Life Instrument (AQoL) [22,23], and Medical Outcome Study 36-Item Short-Form Health Survey (SF-36) [15,17,24-26] are used to assess generic health status.

Previous cross-sectional studies found that diseasespecific and generic health status questionnaires are moderately to strongly correlated in patients with COPD $[17,19,27]$. A longitudinal study among patients with newly detected COPD suggested that changes in a disease-specific health status questionnaire (Chronic Respiratory Disease Questionnaire, CRQ) are significantly correlated with the changes in several sections of a generic health status questionnaire (Nottingham Health Profile, NHP) [28]. However, longitudinal studies analyzing the correlations between disease-specific and generic questionnaires at different time points in patients with advanced COPD are lacking. Therefore, the aims of the current longitudinal observational study were: (1) to determine whether and to what extent a disease-specific questionnaire (SGRQ) correlates with generic health status questionnaires (EQ-5D, AQoL and SF-36) at four different time points in patients with advanced COPD; and (2) to determine the correlation between changes in these health status questionnaires during one-year follow-up.

\section{Methods}

This study is an analysis of a longitudinal observational study concerning symptoms and care needs of patients with advanced chronic organ failure [29]. Methodological details of this study and cross-sectional data about health status, symptom distress, family caregiving and advance care planning in patients with advanced COPD were published before [29-34].

\section{Study population}

Patients with advanced COPD were recruited by their chest physician at the outpatient clinic of one academic and two general hospitals in The Netherlands between January 2008 and June 2009. Patients were included if they had a physician-confirmed diagnosis of severe to very severe COPD (GOLD stages III and IV). Patients were excluded if they were not clinically stable for at least four weeks preceding enrolment (no hospital admission or major change in medication, according to the treating chest physician), if their pharmacological therapy was not optimal (according to the current available guidelines) and stable for at least two months preceding enrolment and if patients lived in a nursing home. All participating patients gave written informed consent. The Medical Ethical Committee of the Maastricht University Medical Centre+ (MUMC+), Maastricht, the Netherlands, approved this study (MEC 07-3-054). The study was registered at the Dutch Trial Register (NTR 1552).

\section{Instruments}

Patients were visited by a member of the research team in their home environment. The following outcomes were assessed at baseline: demographics, weight and height, smoking status, current self-reported comorbidities (Charlson Comorbidity Index) [35], long-term oxygen therapy (LTOT), self-perceived mobility problems, dependency in personal care, and forced expiratory volume in the first second $\left(F E V_{1}\right), F V_{1}$ was calculated from the flow-volume curve measured by a handheld pulmonary spirometer [36]. Severity of dyspnoea was measured using the modified Borg scale (range 0 [nothing at all] to 10 [maximal]) [37]. Symptoms of anxiety and depression were studied using the Hospital Anxiety and Depression scale (HADS), which is divided into an anxiety subscale (HADS-A) and a depression subscale (HADS-D) [38]. Total scores for each subscale range 
from 0 (optimal) to 21 points (worst). Patients were visited at baseline, and four, eight, and 12 months after baseline to assess disease-specific and generic health status using the questionnaires as described below.

\section{Disease-specific health status}

Disease-specific health status was assessed using the SGRQ which consists of 76 items. The SGRQ provides three domain scores (symptoms, activity and impact) and a total score, ranging from 0 (optimal) to 100 points (worst) [39]. A recall period of three months was used.

\section{Generic health status}

Generic health status was assessed using the selfadministered questionnaires EQ-5D [21], AQoL [22] and the SF-36 [24].

EQ-5D is a five-item questionnaire consisting of several items: mobility, self-care, usual activity, pain/discomfort, and anxiety/depression [21]. Each item has three levels: no problems (1), some problems (2), and extreme problems (3). Higher scores on the several items indicate more severe problems. An index score is provided which ranges from -0.59 (worst) to 1.0 (best) [21]. In addition, patients rated their current health using a visual analogue scale (VAS). VAS score ranges from 0 (death or worst possible health) to 100 (best possible health).

AQoL consists of 15 items divided into five domains: illness, independent living, social relationships, physical senses, and psychological well-being [22]. Total score ranges from -0.04 (worst) to 1.00 (best) [40].

SF-36 consists of 36 items divided into eight domains: physical functioning, role-physical, bodily pain, general health, vitality, social functioning, role-emotional, and mental health. For each domain, scores range from 0 (worst) to 100 points (best) [24]. A Physical Component Summary measure (PCS) and a Mental Component Summary measure (MCS) are provided using norm-based methods with scores from a Dutch general population [41]. These summary measure scores are transformed to create a minimum and maximum possible score of 0 and 100 points. All scores below 50 points can be interpreted as below the general population norm [24].

\section{Statistics}

Categorical variables were described as frequencies. Continuous variables were tested for normality and were described as mean and standard deviation (SD). Only patients who completed all four visits were included in the analyses. To compare baseline characteristics between patients who completed the study and those who withdrew from the study, an independent sample $t$-test or Mann-Whitney $U$ test was used, as appropriate. For categorical variables, a Chi square test was used. Depending on the variable distribution, a paired sample $t$-test or Wilcoxon Signed-Rank test was performed to compare the baseline scores of the health status questionnaires with the follow up scores at four, eight, and 12 months. To visualize the correlations between the SGRQ total score and the EQ-5D index score, AQoL total score, and SF-36 PCS and MCS score at baseline, scatterplots were constructed. Furthermore, correlations of the changes in SGRQ total score and EQ-5D index score, AQoL total score, and SF-36 PCS and MCS score and the correlations of the changes in generic health status questionnaires between baseline and four months, four and eight months, and eight and 12 months were shown using scatterplots. To illustrate the correlations of the baseline EQ-5D, AQoL, SF-36 PCS and MCS scores and the correlations of the changes between these generic health status questionnaires, scatterplots were constructed. Additionally, bivariate correlations (Pearson's product-moment correlation) were performed. Strength of correlation was classified as follows: absent $(< \pm 0.20)$, weak $( \pm 0.20$ to \pm 0.34$)$, moderate $( \pm 0.35$ to $\pm 0.50)$, and strong $(> \pm 0.50)[19,42]$. The agreement in the direction of change in SGRQ total score and EQ-5D index score, AQoL total score, and SF-36 PCS and MCS score was determined. The four-months changes were classified into: no change, improvement and deterioration. For generic questionnaires, improvement is defined as a change $>0+\left(1.96^{*} \mathrm{SE}\right.$ of mean change $)$, deterioration is defined as a change $<0-(1.96 * \mathrm{SE}$ of mean change), otherwise no change. For SGRQ improvement is defined as a change $<0-(1.96 * \mathrm{SE}$ of mean change $)$, deterioration is defined as a change $>0+(1.96 * \mathrm{SE}$ of mean change), otherwise no change. Cohen's Kappa was used to test agreement. Kappa values were categorized as poor $(<0.0)$, slight $(0.00-0.20)$, fair $(0.21-0.40)$, moderate (0.41-0.60), substantial (0.61-0.80), and almost perfect (0.81-1.00) agreement [43]. A p-value $\leq 0.05$ was interpreted as statistically significant [44]. All statistical analyses were performed using SPSS for Windows, Version 19.0.

\section{Results}

\section{Baseline characteristics}

In total, 105 COPD patients were included (Table 1). Most patients had very severe COPD (GOLD stage IV: $\mathrm{n}=77,73.3 \%)$. Fifty-nine percent of the patients used long-term oxygen therapy. Patients were generally slightly overweight, and $85 \%$ of the patients experienced mobility problems. Patients who withdrew from the study were more frequently dependent in personal care than patients who completed the study.

\section{Health status}

At baseline, patients generally had an impaired diseasespecific and generic health status (Table 2). Patients who 
Table 1 Baseline patient characteristics

\begin{tabular}{|c|c|c|c|c|}
\hline & Total sample $(n=105)$ & Study completed $(n=86)$ & Dropout $(n=19)$ & p-value ${ }^{c}$ \\
\hline Male, n (\%) & $65(61.9)$ & $54(62.8)$ & $11(57.9)$ & 0.69 \\
\hline Age, years & $66.3(9.2)$ & $65.7(9.3)$ & $68.8(8.2)$ & 0.18 \\
\hline $\mathrm{BMl}, \mathrm{kg} / \mathrm{m}^{2 \mathrm{~d}}$ & $26.3(6.7)$ & $26.5(6.9)$ & $25.5(5.4)$ & 0.99 \\
\hline Current smokers, n (\%) & $26(24.8)$ & $23(26.7)$ & $3(15.8)$ & 0.69 \\
\hline $\mathrm{FEV}_{1}, \%$ predicted $^{\mathrm{d}}$ & $34.1(13.5)^{a}$ & $34.4(13.6)^{b}$ & $32.7(13.1)$ & 0.60 \\
\hline Charlson index, points & $2.5(1.7)$ & $2.4(1.7)$ & $2.7(1.7)$ & 0.50 \\
\hline Long-term oxygen therapy, n (\%) & $62(59.0)$ & $53(61.6)$ & $9(47.4)$ & 0.26 \\
\hline Borg scale (dyspnea), points & $4.8(2.0)$ & $4.8(2.0)$ & $4.9(2.1)$ & 0.79 \\
\hline Borg scale (fatigue), points & $4.6(2.5)$ & $4.4(2.4)$ & $5.3(2.8)$ & 0.15 \\
\hline HADS-A score, points & $5.9(4.5)$ & $5.5(4.2)$ & $7.5(5.6)$ & 0.16 \\
\hline HADS-D score, points & $6.3(4.0)$ & $6.0(4.0)$ & $7.7(3.4)$ & 0.10 \\
\hline Self-perceived mobility problems, n (\%) & $89(84.8)$ & $72(83.8)$ & $17(89.5)$ & 0.33 \\
\hline Dependent in personal care, $\mathrm{n}(\%)$ & $47(44.8)$ & $33(38.4)$ & $14(73.6)$ & 0.009 \\
\hline
\end{tabular}

Values expressed as mean (standard deviation [SD]), number of patients (n), proportion (\%).

Abbreviations: BMI, body mass index; $\mathrm{FEV}_{1}$, forced expiratory volume in the first second; HADS-A, Hospital Anxiety and Depression Scale, Anxiety subscale; HADS-D, Hospital Anxiety and Depression Scale, Depression subscale. ${ }^{a} n=102 ;{ }^{b} n=83 ;{ }^{c}$ comparison between patients who completed the study and patients who withdrew from the study; ${ }^{d}$ non parametric statistic tests were used because of skewed data.

withdrew from the study reported worse scores on the SGRQ impact domain, several domains of the EQ-5D and AQoL, the EQ-5D index score and AQoL total score compared to patients who completed all four visits.

On average, patients who completed the study $(n=84)$ reported 1.1 (1.1) exacerbations during 12 months followup. Generic health status scores at baseline and 12 months after baseline were comparable between patients who had no exacerbations during 12 months $(n=33)$ and patients who had one or more exacerbations during 12 months $(\mathrm{n}=51)(\mathrm{p}>0.05)$. Patients who experienced one or more exacerbations during 12 months reported a worse SGRQ total score (58.3 (16.3) points) at baseline compared to patients who had no exacerbation during 12 months (50.7 (14.6) points), $\mathrm{p}=0.03$.

Table 3 shows the changes in health status over time. SGRQ total score, EQ-5D index score, and SF-36 PCS and MCS scores remained stable over time. Patients reported worse AQoL total scores at eight and 12 months compared to baseline.

\section{Correlations}

Correlations between SGRQ total scores and the EQ-5D index score, AQOL total score, and SF-36 PCS and MCS scores were weak to strong at the four different time points (Table 4).

Figure $1 \mathrm{a}$ to $1 \mathrm{~h}$ show the correlations between the SGRQ total scores and EQ-5D index scores, AQoL total scores and SF-36 PCS and MCS scores at all time points, and the correlations between the changes in SGRQ total scores and the changes in EQ-5D index scores, AQoL total scores and SF-36 PCS and MCS scores. At baseline, disease-specific and generic health status questionnaires were moderately to strongly correlated, while the correlations between the changes were weak or absent.

Furthermore, at baseline, generic health status questionnaires were moderately to strongly correlated. The correlations between the changes were weak to moderate while the changes in AQoL total score were not correlated with the changes in SF-36 PCS score (Figures 2a to 2j).

\section{Agreement}

Table 5 shows the agreement of the direction of changes in SGRQ total scores with the direction of changes in EQ-5D index score, AQoL total score, SF-36 PCS and SF-36 MCS scores. The direction of changes in SGRQ total scores agreed slightly (Kappa ranged from 0.12 to $0.18, \mathrm{p}<0.05)$ with the direction of changes in EQ-5D index score, AQoL total score and SF-36 PCS score.

The direction of changes in EQ-5D index score agreed fairly with the direction of changes in AQoL total score and SF-36 PCS score (Kappa ranged from 0.21 to 0.34, $\mathrm{p}<0.05)$. The direction of changes in AQoL total score agreed moderately with the direction of changes in SF-36 PCS score $(K=0.41, p<0.001)$. There was no agreement between the direction of changes in SF-36 PCS score and the direction of changes in EQ-5D index score $(K=0.17$, $\mathrm{p}=0.07)$ and AQoL total score $(\mathrm{K}=0.15, \mathrm{p}=0.17)$.

\section{Discussion}

\section{Key findings}

The current study shows that the SGRQ total score and the EQ-5D index score, AQoL total score, and SF-36 PCS score were moderately to strongly correlated at four consecutive time points in patients with advanced COPD, while SGRQ total scores were weakly correlated 
Table 2 Baseline health status

\begin{tabular}{|c|c|c|c|c|c|}
\hline Questionnaire & Domain & Total sample $(n=105)$ & Study completed $(n=86)$ & Dropout $(n=19)$ & $p$-value \\
\hline \multirow[t]{7}{*}{ EQ-5D } & Mobility $^{d}$ & $1.87(0.39)$ & $1.85(0.39)$ & $1.95(0.40)$ & 0.33 \\
\hline & Self-Care & $1.70(0.66)$ & $1.60(0.62)$ & $2.16(0.69)$ & 0.001 \\
\hline & Usual activities & $2.08(0.65)$ & $1.99(0.60)$ & $2.47(0.70)$ & 0.01 \\
\hline & Pain/discomfort & $1.55(0.66)$ & $1.56(0.64)$ & $1.53(0.77)$ & 0.85 \\
\hline & Anxiety/depression & $1.50(0.67)$ & $1.47(0.66)$ & $1.68(0.67)$ & 0.20 \\
\hline & Index score & $0.51(0.33)$ & $0.55(0.30)$ & $0.33(0.37)$ & 0.008 \\
\hline & VAS & $62.6(14.0)$ & $64.1(13.2)$ & $55.8(15.9)$ & 0.02 \\
\hline \multirow[t]{6}{*}{ AQoL } & Illness $^{d}$ & $0.17(0.17)$ & $0.18(0.16)$ & $0.12(0.19)$ & 0.04 \\
\hline & Independent living & $0.58(0.30)$ & $0.63(0.27)$ & $0.36(0.31)$ & $<0.0005$ \\
\hline & Social relationships ${ }^{d}$ & $0.83(0.20)$ & $0.85(0.20)$ & $0.77(0.20)$ & 0.06 \\
\hline & Physical senses $^{d}$ & $0.92(0.11)$ & $0.93(0.09)$ & $0.86(0.18)$ & 0.17 \\
\hline & Psychological wellbeing & $0.87(0.13)$ & $0.97(0.13)$ & $0.85(0.15)$ & 0.50 \\
\hline & Total & $0.46(0.28)$ & $0.50(0.27)$ & $0.29(0.30)$ & 0.005 \\
\hline \multirow[t]{10}{*}{ SF-36 } & Physical Functioning $^{d}$ & $21.0(21.1)$ & $22.3(20.8)$ & $15.5(22.4)$ & 0.07 \\
\hline & Role-physical $^{d}$ & $37.1(42.8)$ & $38.4(43.2)$ & $31.6(41.5)$ & 0.61 \\
\hline & Bodily pain $^{d}$ & 70.9 (29.5) & $72.8(28.3)$ & $62.3(34.0)$ & 0.23 \\
\hline & General health & $29.7(19.1)$ & $30.1(19.2)$ & $28.2(19.3)$ & 0.70 \\
\hline & Vitality & $51.1(18.9)$ & $51.3(19.1)$ & $50.3(18.7)$ & 0.83 \\
\hline & Social functioning & $65.0(26.1)$ & $67.0(25.7)$ & $55.9(27.1)$ & 0.10 \\
\hline & Role-emotional $^{d}$ & $62.9(44.9)$ & $63.6(44.7)$ & $59.7(46.6)$ & 0.80 \\
\hline & Mental health & $68.6(19.9)$ & $69.7(19.3)$ & $63.8(22.2)$ & 0.25 \\
\hline & $P C S^{d}$ & $22.4(9.6)$ & $22.9(9.2)$ & $19.8(11.3)$ & 0.08 \\
\hline & MCS & $47.3(14.1)$ & $47.7(14.4)$ & $45.1(15.4)$ & 0.48 \\
\hline \multirow[t]{4}{*}{ SGRQ } & Symptoms & $58.6(22.5)^{\mathrm{a}}$ & $59.3(22.9)^{b}$ & $55.4(25.5)$ & 0.52 \\
\hline & Activity $^{d}$ & $74.8(21.9)^{a}$ & $73.6(21.3)^{b}$ & $80.1(24.3)$ & 0.06 \\
\hline & Impact & $45.2(18.5)^{\mathrm{a}}$ & $43.6(17.7)^{b}$ & $52.7(20.4)$ & 0.04 \\
\hline & Total $^{d}$ & $56.5(21.8)^{a}$ & $55.3(16.0)^{b}$ & $61.5(19.7)$ & 0.09 \\
\hline
\end{tabular}

Values expressed in points as mean (standard deviation [SD]). Bold printed numbers show significant ( $\mathrm{p} \leq 0.05)$ results. Abbreviations: EQ-5D, European Quality of Life-5 dimensions; VAS, Visual Analogue Scale; AQoL, Assessment of Quality of Life instrument; SF-36, Short Form 36-item health survey; PCS, Physical Component Summary measure; MCS, Mental Component Summary measure; SGRQ, St. George Respiratory Questionnaire. ${ }^{a} n=103 ;{ }^{b} n=84 ;{ }^{c}$ comparison between patients who completed the study and patients who withdrew from the study; ${ }^{d}$ non parametric statistic tests were used because of skewed data.

with SF-36 MCS scores at four, eight and 12 months after baseline. The correlations between changes over time were weak or even absent. This is probably due to a poor or absent agreement in the direction of changes in the different health status questionnaires.

Previous cross-sectional studies found moderate to strong correlations between disease-specific and generic health status questionnaires in patients with COPD $[19,27]$. The current longitudinal study extends these findings and shows that SGRQ total scores were moderately to strongly correlated with the EQ-5D index score, AQoL total score, and SF-36 PCS score at four consecutive time points during one year follow-up. SGRQ total scores were weakly correlated with SF-36 MCS scores at four, eight, and 12 months. This can be explained by the fact that the SF-36 MCS focusses on mental aspects of health status, while the SGRQ total score includes several components of disease-specific health status. These findings are in line with Katsura et al. who reported even no correlation $(r=0.19)$ between the SGRQ total score and SF-36 MCS score in elderly patients with COPD [45].

Generic health status questionnaires were moderately to strongly correlated, while the correlations between the changes were weak to moderate. Pickard et al. found similar data in a cross-sectional study including inpatients and outpatients diagnosed with COPD concerning the EQ-5D index score and SF-36 PCS and MCS score [19]. EQ-5D index score showed the best correlation with AQoL total score, at baseline and between changes over time. Holland et al. compared the AQoL and EQ5D in elderly patients admitted to an acute hospital and found a comparable correlation of the baseline scores 
Table 3 Health status at baseline, 4, 8 and 12 months

\begin{tabular}{|c|c|c|c|c|c|}
\hline Questionnaire & Domain & Baseline & 4 months & 8 months & 12 months \\
\hline \multirow[t]{7}{*}{$\overline{E Q-5 D}$} & Mobility $^{c}$ & $1.85(0.39)$ & $1.83(0.44)$ & $1.90(0.41)$ & $1.97(0.32)^{b}$ \\
\hline & Self-Care & $1.60(0.62)$ & $1.67(0.68)$ & $1.78(0.66)^{b}$ & $1.76(0.68)^{b}$ \\
\hline & Usual activities & $1.99(0.60)$ & $2.15(0.58)^{b}$ & $2.14(0.58)^{b}$ & $2.13(0.70)$ \\
\hline & Pain/discomfort & $1.56(0.64)$ & $1.40(0.60)^{b}$ & $1.55(0.66)$ & $1.47(0.61)$ \\
\hline & Anxiety/depression & $1.47(0.66)$ & $1.35(0.63)^{b}$ & $1.41(0.62)$ & $1.33(0.61)^{b}$ \\
\hline & Index score & $0.55(0.30)$ & $0.57(0.31)$ & $0.52(0.32)$ & $0.51(0.31)$ \\
\hline & VAS & $64.1(13.2)$ & $61.7(15.1)$ & $61.9(14.5)$ & $60.6(13.4)^{b}$ \\
\hline \multirow[t]{6}{*}{ AQoL } & Illness & $0.18(0.16)$ & $0.23(0.16)^{b}$ & $0.24(0.16)^{b}$ & $0.24(0.17)^{b}$ \\
\hline & Independent living & $0.63(0.27)$ & $0.59(0.28)$ & $0.54(0.28)^{b}$ & $0.53(0.29)^{\mathrm{b}}$ \\
\hline & Social relationships ${ }^{c}$ & $0.85(0.20)$ & $0.82(0.21)$ & $0.81(0.21)$ & $0.84(0.18)$ \\
\hline & Physical senses & $0.93(0.09)$ & $0.94(0.08)$ & $0.93(0.09)$ & $0.94(0.08)$ \\
\hline & Psychological wellbeing & $0.97(0.13)$ & $0.90(0.12)^{b}$ & $0.90(0.14)$ & $0.91(0.11)^{b}$ \\
\hline & Total & $0.50(0.27)$ & $0.48(0.26)$ & $0.44(0.26)^{b}$ & $0.45(0.24)^{b}$ \\
\hline \multirow[t]{10}{*}{ SF-36 } & Physical Functioning & $22.3(20.8)$ & $19.9(20.0)$ & $21.6(20.2)$ & $20.3(21.4)$ \\
\hline & Role-physical $^{\complement}$ & $38.4(43.2)$ & $37.8(45.0)$ & $48.8(46.8)$ & $41.9(46.9)$ \\
\hline & Bodily pain & $72.8(28.3)$ & $75.2(29.0)$ & $72.0(30.4)$ & $76.5(28.9)$ \\
\hline & General health & $30.1(19.2)$ & $27.6(18.2)$ & $28.5(16.7)$ & $28.2(19.9)$ \\
\hline & Vitality & $51.3(19.1)$ & $53.9(17.9)$ & $53.4(17.0)$ & $52.7(18.3)$ \\
\hline & Social functioning & $67.0(25.7)$ & $67.6(26.7)$ & $62.7(28.6)$ & $63.2(28.7)$ \\
\hline & Role-emotional $\left.\right|^{c}$ & $63.6(44.8)$ & $67.8(42.9)$ & $67.1(45.0)$ & $70.2(43.7)$ \\
\hline & Mental health & $69.7(19.3)$ & $70.6(19.7)$ & $69.4(18.6)$ & $69.4(17.6)$ \\
\hline & PCS & $22.9(9.2)$ & $21.8(9.6)$ & $23.4(10.5)$ & $22.6(10.4)$ \\
\hline & MCS & $47.7(14.4)$ & $49.5(14.6)$ & 47. $6(14.4)$ & $48.5(13.2)$ \\
\hline \multirow[t]{4}{*}{$\mathrm{SGRQ}^{\mathrm{a}}$} & Symptoms & $59.3(22.9)$ & $56.4(20.9)$ & $57.2(19.4)$ & $58.2(18.2)$ \\
\hline & Activity & $73.6(21.3)$ & $77.1(18.2)$ & $74.1(22.1)$ & $76.8(19.7)$ \\
\hline & Impact & $43.6(17.7)$ & $43.6(16.0)$ & $42.3(17.0)$ & $43.3(17.5)$ \\
\hline & Total & $55.3(16.0)$ & $55.9(14.5)$ & $54.3(16.2)$ & $56.3(15.2)$ \\
\hline
\end{tabular}

Values expressed in points as mean (standard deviation [SD]). Bold printed numbers show significant ( $\mathrm{p} \leq 0.05)$ results. Abbreviations: please see legend Table 2 .

${ }^{a} \mathrm{n}=84 ;{ }^{\mathrm{b}} \mathrm{p}=\leq 0.05$ vs. baseline; ${ }^{\mathrm{c}}$ non parametric statistic tests were used because of skewed data.

and changes between these two questionnaires as in the present study [46]. Thus, even the generic health status questionnaires lack correlation. Researchers and clinicians should consider carefully which questionnaire is in line with their individual study objectives and study population. To the best of our knowledge, the AQoL has not been used as generic health status questionnaire in patients with COPD before. The current findings may

Table 4 Correlations between SGRQ total score and generic health status questionnaires

\begin{tabular}{lcccc}
\hline & Baseline & 4 months & 8 months & 12 months \\
\hline EQ-5D index score & -0.536 & -0.439 & -0.487 & -0.421 \\
AQoL total score & -0.617 & -0.547 & -0.587 & -0.496 \\
SF-36, PCS score & -0.679 & -0.469 & -0.464 & -0.559 \\
SF-36, MCS score & -0.489 & -0.296 & -0.314 & -0.285 \\
\hline
\end{tabular}

$\mathrm{n}=84$, all correlation: $\mathrm{p} \leq 0.01$.

Abbreviations: Please see legend Table 2. suggest that the AQoL can be used to assess health status in outpatients with advanced COPD. However, future research is needed to support these results.

To the best of our knowledge, this is the first longitudinal study exploring the correlations (at four consecutive time points as well as the changes between these time points) between the SGRQ and the EQ-5D, AQoL, and SF-36 in patients with advanced COPD. Previously, improved health status (measured by SGRQ and SF-36) was found in patients with COPD who followed pulmonary rehabilitation or received home care [47-49]. Thus, it seemed reasonable to hypothesize that changes in disease-specific and generic health status questionnaires were somehow correlated. However, in the present study, the correlations between the changes in SGRQ total scores and in AQoL total scores as well as SF-36 MCS scores were absent. The changes in SGRQ total score and EQ-5D index score and SF-36 PCS 
a)

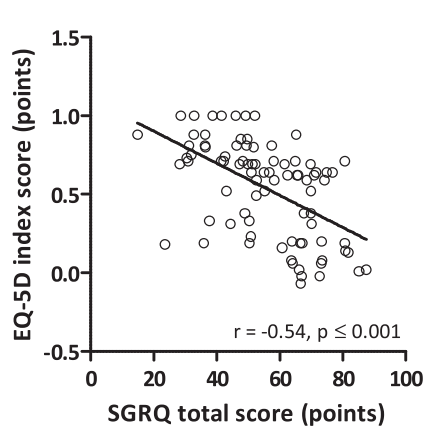

c)
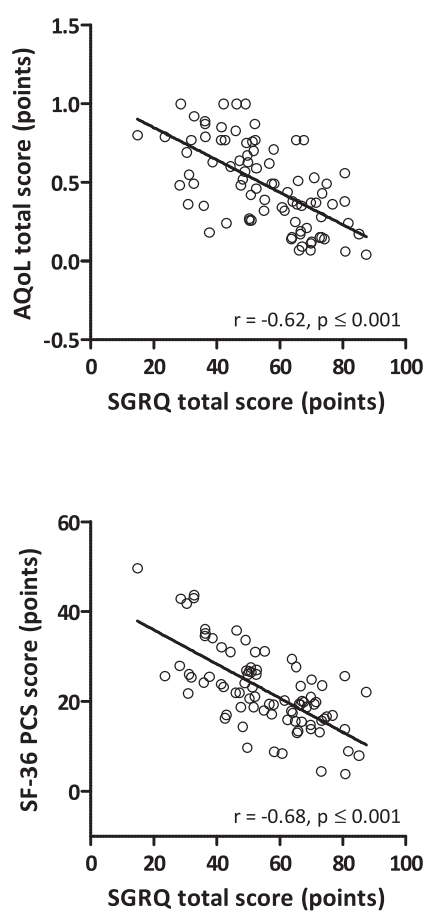

g)

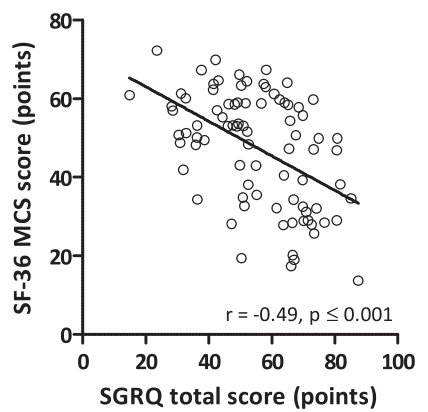

b)

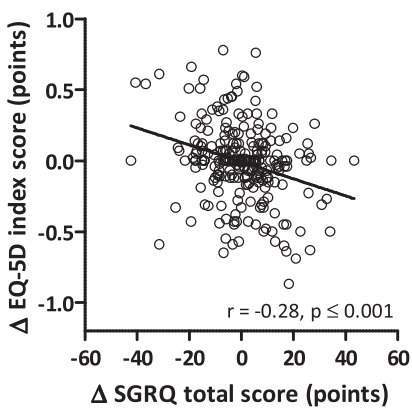

d)

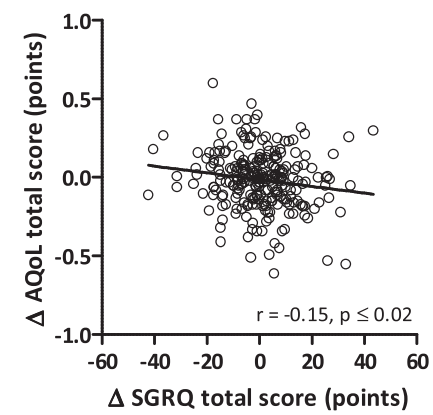

f)

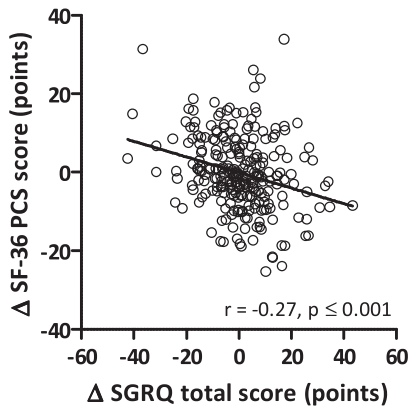

h)

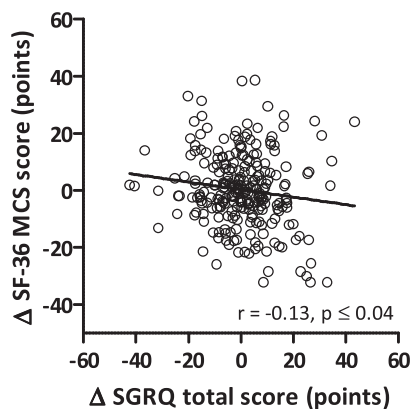

Figure 1 Correlation between SGRQ total score and EQ-5D index score (a), AQoL total score (c), SF-36 PCS score (e) and SF-36 MCS score $(\mathrm{g})$ at baseline and correlation between changes between 0-4 months, 4-8 months and 8-12 months of SGRQ total score and changes of EQ-5D index score (b), AQoL total score (d), SF-36 PCS (f) and SF-36 MCS score (h) (all data points together); $n=84$; $\Delta$, change in. 
a)
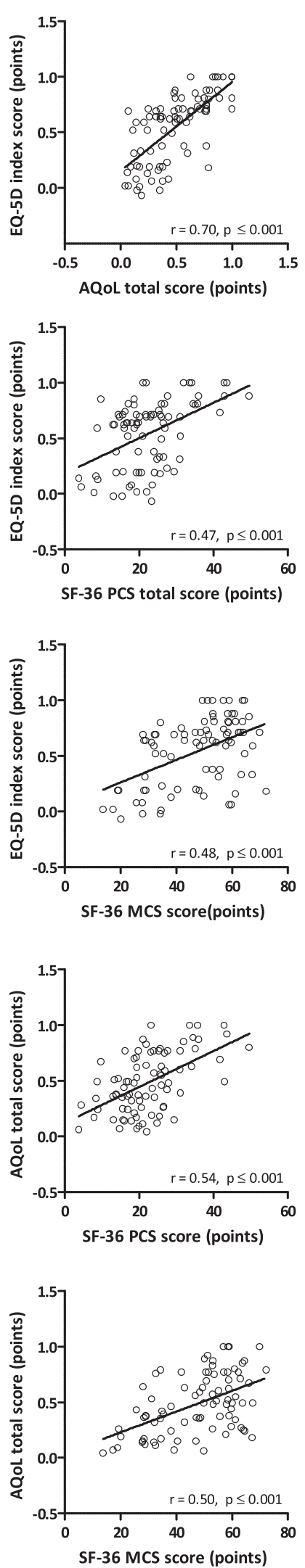

b)
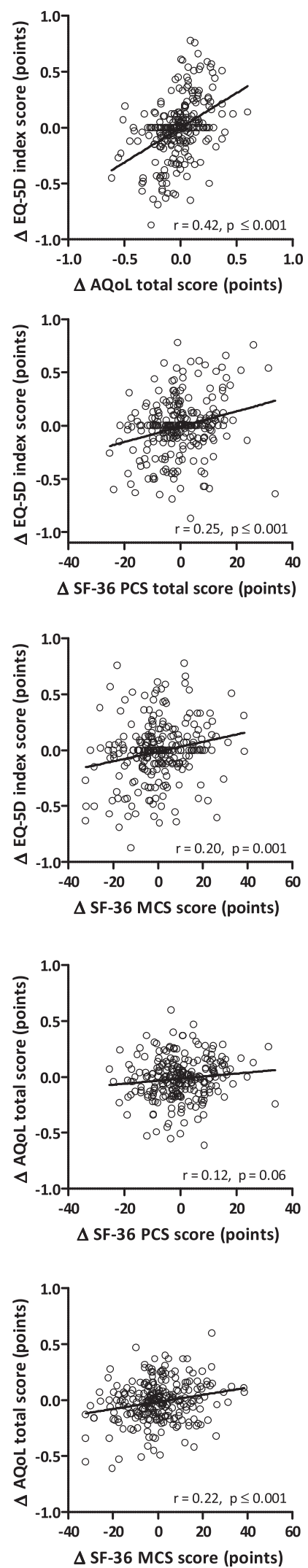

Figure 2 (See legend on next page.) 
(See figure on previous page.)

Figure 2 Correlation between EQ-5D index score and AQoL total score (a), SF-36 PCS score (c), SF-36 MCS score (e) and correlation between AQoL total score and SF-36 PCS score (g) and SF-36 MCS score (i) at baseline and correlation between changes from 0-4 months, 4-8 months and 8-12 months of EQ-5D index score and changes of AQoL total score (b), SF-36 PCS score (d), SF-36 MCS score (f) and changes of AQoL total score and SF-36 PCS score (h) and SF-36 MCS score (j) (all data points together); $n=84 ; \Delta$, change in.

scores were weakly correlated. These weak or absent correlations can be explained by the fact that the direction of changes in SGRQ total scores and EQ-5D index score, AQoL total scores and SF-36 PCS score just slightly agree. There was even no agreement on the direction of change in SGRQ total score and SF-36 MCS score. The agreement on the direction of change in disease-specific and generic health status was about $45 \%$, while in 25 to $35 \%$ of the patients the observed four months changes were in opposite direction (Table 5). Ritva et al. compared the changes measured by SGRQ and $15 \mathrm{D}$, a 15 dimensional generic health status questionnaire, among asthmatic patients and concluded that these instruments agreed on direction of change in health status in $64.8 \%$ of patients. In $15.8 \%$ of the cases the changes were in an opposite direction. In the remaining patients, health status changed according to one questionnaire [50]. However, Ritva et al. assessed changes in health status during three years [50], while we studied changes in health status during one year.

The current results support that healthcare professionals should use disease-specific as well as generic instruments to gain insight into the disease-specific and general impact of the disease and to get an in depth understanding of patients' health status. Indeed, diseasespecific questionnaires include relevant questions related to the patient's disease and may generally be more sensitive to the disease and small changes in health status [17]. Generic health status questionnaires are intended for general use and are universally applicable: they tend to cover a broad variety of aspects (e.g. functional states, perceptions, social opportunities) [14,17]. Indeed, disease-specific instruments may be more responsive to change in clinical status or more sensitive in distinguishing patients with different disease severities while generic measures may be more likely to detect unexpected events which are probably not related to the disease and detect effects of diverse aspects on a disease [5]. The current study revealed that patients who experienced one or more exacerbations during 12 months reported a worse SGRQ total score at baseline compared to patients who had no exacerbation during 12 months while there were no significant differences according to the generic measurements. This may illustrate the disease-specific qualities of the SGRQ: the SGRQ may be more sensitive to detect differences in clinical status in patients with respiratory diseases. On the other hand, the AQoL showed changes over one year in total score and several domain scores (e.g., "independent living" or "illness") while the SGRQ did not show changes over one year. This underlines the fact that generic and disease-specific instruments measure different aspects and cannot replace each other. Combining both types of questionnaires allows healthcare professionals to identify targets for interventions as well as to evaluate the effects of these interventions [13].

Recently, Pakhale et al. constructed a new questionnaire (McGill-COPD Quality of Life Questionnaire) by combining items of a disease-specific questionnaire with qualities of a generic questionnaire to measure health status in COPD patients [51]. Combining items of different measures can reduce patients' load and increase their attention and participation. But it is still not clear which questionnaires or items in terms of psychometric properties (e.g. validity, reliability, sensitivity to change) are most suitable to use for combination. The McGill-COPD Quality of Life Questionnaire suggests possibilities. However, this questionnaire needs to be validated before it can be used in clinical practice or further research.

Interestingly, participants in the present study reported a better generic health status over time according to the AQoL illness domain, while the AQoL total score showed worse generic health status. This was also true for some EQ-5D domains and the EQ-5D VAS score (Table 3). These findings show that domain scores as well as total scores should be examined to achieve a correct understanding of patients' health status. Furthermore, our results may suggest that the AQoL is more sensitive to detect changes than the SF-36 or SGRQ. However, the current study did not focus on sensitivity of health status questionnaires. A lack of previous studies using the AQoL as generic health status measure underlines the importance of further research in this field.

The present study has some methodological considerations that should be considered in interpreting the results. First, the study population consists of a convenience sample of patients with advanced COPD. Thus, it remains unknown whether these data are applicable for patients with GOLD stage I or II. Second, about $20 \%$ of the baseline study sample withdrew from the study during one year follow-up. These patients were more dependent in personal care and reported a worse baseline generic health status than patients who completed the study. It may be possible that changes in disease-specific and generic health status 
Table 5 Direction of 4-months changes in SGRQ total score and EQ-5D index score, AQoL total score, SF-36 PCS and SF-36 MCS

\begin{tabular}{|c|c|c|c|c|}
\hline & & SGRQ total score & Improvement & Deterioration \\
\hline & & No change & & \\
\hline change in EQ-5D & No change & $12(4.8 \%)$ & $23(9.1 \%)$ & $24(9.5 \%)$ \\
\hline index score & Improvement & $10(4.0 \%)$ & $52(20.6 \%)$ & $31(12.3 \%)$ \\
\hline$(K=0.18)$ & Deterioration & $12(4.8 \%)$ & $32(12.7 \%)$ & $56(22.2 \%)$ \\
\hline change in AQoL & No change & $5(2.0 \%)$ & $6(2.4 \%)$ & $14(5.6 \%)$ \\
\hline total score & Improvement & $14(5.6 \%)$ & $54(21.4 \%)$ & $38(15.1 \%)$ \\
\hline$(K=0.11)$ & Deterioration & $15(6.0 \%)$ & 47 (18.7\%) & $59(23.4 \%)$ \\
\hline change in & No change & $7(2.8 \%)$ & $19(7.5 \%)$ & $12(4.8 \%)$ \\
\hline SF-36 PCS score & Improvement & $10(4.0 \%)$ & $48(19.0 \%)$ & $38(15.1 \%)$ \\
\hline$(K=0.12)$ & Deterioration & $17(6.7 \%)$ & $40(15.9 \%)$ & $61(24.2 \%)$ \\
\hline change in & No change & $7(2.8 \%)$ & $9(3.6 \%)$ & $10(4.0 \%)$ \\
\hline SF-36 MCS score & Improvement & $17(6.7 \%)$ & 49 (19.4\%) & $43(17.1 \%)$ \\
\hline$(K=0.08)$ & Deterioration & $10(4.0 \%)$ & 49 (19.4\%) & $58(23.0 \%)$ \\
\hline
\end{tabular}

Abbreviations: please see legend Table 2.

$K$, Cohen's Kappa; bold printed numbers show significant $(p \leq 0.05)$ results.

were different among patients who completed the study and patients who withdrew from the study. However, total scores of the disease-specific questionnaire SGRQ were comparable with findings from previous studies $[6,19]$. Third, the duration of the follow-up period is limited. However, longitudinal studies among elderly with advanced chronic diseases are scarce and recruitment and sustained participation is challenging in this population $[52,53]$. Fourth, ceiling effects and floor effects in longitudinal studies can limit the results because changes cannot be adequately detected. However, the proportion of patients reporting the highest possible score on the disease-specific and generic questionnaires ranged from $1.2-8.3 \%$ for all data points, while none of the patients reported the lowest possible score on any of the diseasespecific and generic health status questionnaires on any of the data points. Because ceiling effects and floor effects are considered to be present if more than $15 \%$ of the subjects score the highest or lowest possible value, respectively [54], the influence of ceiling effects and floor effects seems to be limited in the current study. Fifth, the current findings need to be interpreted in the light of the number of comparisons that were made in the present study. Nonetheless, multiple findings in the same direction, rather than a single statistically significant result, suggest that these are not due to chance alone. Moreover, 'Bonferoni adjustments are at best, unnecessary and, at worst, deleterious to sound statistical inference' [55].

\section{Conclusion and implications}

The current study suggests that health care professionals should use disease-specific as well as generic instruments to gain insight into the disease-specific and general impact of the disease. This is necessary to identify targets for interventions with the aim to improve disease-specific and generic health status and to evaluate the effects of interventions. Future research is required to compare disease-specific and generic health status questionnaires in a broader population. In addition, the possibilities and characteristics of a combined instrument measuring health status in patients with advanced COPD should be studied.

\section{Abbreviations}

AQoL: Assessment of Quality of Life instrument; BMI: Body mass index; COPD: Chronic Obstructive Pulmonary Disease; EQ-5D: European Quality of life-5 Dimensions; FEV : Forced expiratory volume in the first second; GOLD: Global initiative for chronic Obstructive Lung Disease; HADS: Hospital Anxiety and Depression Scale; LTOT: Long-term oxygen therapy; SF36: Medical Outcomes Study 36-Item Short-Form Health Survey; SGRQ: Saint George's Respiratory Questionnaire.

\section{Competing interests}

The authors declare that they have no competing interests.

\section{Authors' contributions}

SW was responsible for analysis and interpretation of data and drafting the article. DJAJ and MAS were responsible for conception and design, acquisition of data, analysis and interpretation of data and drafting the article. JMGAS, FMEF and EFMW contributed to the study conception and design and interpretation of data. All authors read and approved the final manuscript.

\section{Acknowledgements}

This project was supported by: Proteion Thuis, Horn, The Netherlands; CIRO+, Horn, The Netherlands; Grants 3.4.10.015 (S. Wilke) and 3.4.06.082 (D.J.A. Janssen) of the Netherlands Asthma Foundation, Leusden, The Netherlands; Stichting Wetenschapsbevordering Verpleeghuiszorg (SWBV), Utrecht, The Netherlands. The present authors are grateful to research nurses Mrs Els Verstraeten en Mrs Jamila Dekker-Heuts for collection of the data and to Mrs Linda Koolen for input of the data. The present authors are grateful to the doctors of the following collaborating hospitals and departments for their participation in this study: Maastricht University Medical Centre+ (MUMC+), Maastricht, the Netherlands: Department of Respiratory Medicine; Laurentius 
Hospital, Roermond, the Netherlands; Department of Respiratory Medicine; Catharina hospital, Eindhoven, the Netherlands: Department of Respiratory Medicine.

\section{Author details}

${ }^{1}$ Program Development Centre, $\mathrm{CIRO}+$, centre of expertise for chronic organ failure, Hornerheide 1, Horn, NM 6085, The Netherlands. ${ }^{2}$ CAPHRI, Maastricht University, Maastricht, The Netherlands. ${ }^{3}$ Proteion Thuis, Horn, The Netherlands. ${ }^{4}$ Department of Respiratory Medicine, Maastricht University Medical Centre+ (MUMC+), Maastricht, The Netherlands. ${ }^{5}$ Department of General Practice and Department of Health Services Research, Faculty of Health, Medicine and Life Sciences/CAPHRI, Maastricht University, Maastricht, The Netherlands.

Received: 13 March 2012 Accepted: 16 August 2012 Published: 21 August 2012

\section{References}

1. Rabe KF, Hurd S, Anzueto A, Barnes PJ, Buist SA, Calverley P, Fukuchi Y, Jenkins C, Rodriguez-Roisin R, van Weel C, Zielinski J: Global strategy for the diagnosis, management, and prevention of chronic obstructive pulmonary disease: GOLD executive summary. Am J Respir Crit Care Med 2007, 176:532-555

2. Kessler R, Partridge MR, Miravitlles M, Cazzola M, Vogelmeier C, Leynaud D, Ostinelli J: Symptom variability in patients with severe COPD: a pan-European cross-sectional study. Eur Respir J 2011 37:264-272.

3. Vaes AW, Wouters EF, Franssen FM, Uszko-Lencer NH, Stakenborg KH, Westra M, Meijer K, Schols AM, Janssen PP, Spruit MA: Task-related oxygen uptake during domestic activities of daily life in patients with COPD and healthy elderly subjects. Chest 2011, 140:970-979.

4. Annegarn J, Meijer K, Passos VL, Stute K, Wiechert J, Savelberg HH, Schols AM, Wouters EF, Spruit MA: Problematic Activities of Daily Life are Weakly Associated With Clinical Characteristics in COPD. J Am Med Dir Assoc 2012, 13:284-290.

5. Curtis JR, Patrick DL: The assessment of health status among patients with COPD. Eur Respir J Suppl 2003, 41:36s-45s.

6. Jones PW, Brusselle G, Dal Negro RW, Ferrer M, Kardos P, Levy ML, Perez T, Soler-Cataluna JJ, van der Molen T, Adamek L, Banik N: Health-related quality of life in patients by COPD severity within primary care in Europe. Respir Med 2011, 105:57-66.

7. Janssen DJ, Spruit MA, Leue C, Gijsen C, Hameleers H, Schols JM, Wouters EF: Symptoms of anxiety and depression in COPD patients entering pulmonary rehabilitation. Chron Respir Dis 2010, 7:147-157.

8. Spruit MA, Pennings HJ, Janssen PP, Does JD, Scroyen S, Akkermans MA, Mostert R, Wouters EF: Extra-pulmonary features in COPD patients entering rehabilitation after stratification for MRC dyspnea grade. Respir Med 2007, 101:2454-2463.

9. Dodd JW, Hogg L, Nolan J, Jefford H, Grant A, Lord VM, Falzon C, Garrod R Lee C, Polkey Ml, et al: The COPD assessment test (CAT): response to pulmonary rehabilitation. A multicentre, prospective study. Thorax 2011, 66:425-429.

10. Moullec G, Laurin C, Lavoie KL, Ninot G: Effects of pulmonary rehabilitation on quality of life in chronic obstructive pulmonary disease patients. Curr Opin Pulm Med 2011, 17:62-71.

11. Nici L, ZuWallack R, Wouters E, Donner CF: On pulmonary rehabilitation and the flight of the bumblebee: the ATS/ERS Statement on Pulmonary Rehabilitation. Eur Respir J 2006, 28:461-462.

12. Spruit MA, Vanderhoven-Augustin I, Janssen PP, Wouters EF: Integration of pulmonary rehabilitation in COPD. Lancet 2008, 371:12-13

13. Cazzola M, MacNee W, Martinez FJ, Rabe KF, Franciosi LG, Barnes PJ, Brusasco V, Burge PS, Calverley PM, Celli BR, et al: Outcomes for COPD pharmacological trials: from lung function to biomarkers. Eur Respir J 2008, 31:416-469.

14. Patrick DL, Deyo RA: Generic and disease-specific measures in assessing health status and quality of life. Med Care 1989, 27:S217-S232.

15. Esteban C, Quintana JM, Aburto M, Moraza J, Equrrola M, Perez-Izquierdo J, Aizpiri S, Aguirre U, Capelastegui A: Impact of changes in physical activity on health-related quality of life among patients with COPD. Eur Respir $J$ $2010,36 \cdot 292-300$
16. Habraken JM, van der Wal WM, Ter Riet G, Weersink EJ, Toben F, Bindels PJ: Health-related quality of life and functional status in end-stage COPD: a longitudinal study. Eur Respir J 2011, 37:280-288.

17. Maly M, Vondra V: Generic versus disease-specific instruments in qualityof-life assessment of chronic obstructive pulmonary disease. Methods Inf Med 2006, 45:211-215

18. Menn P, Weber N, Holle R: Health-related quality of life in patients with severe COPD hospitalized for exacerbations - comparing EQ-5D, SF-12 and SGRQ. Health Qual Life Outcomes 2010, 8:39.

19. Pickard AS, Yang Y, Lee TA: Comparison of health-related quality of life measures in chronic obstructive pulmonary disease. Health Qual Life Outcomes 2011, 9:26.

20. Singh SJ, Sodergren SC, Hyland ME, Williams J, Morgan MD: A comparison of three disease-specific and two generic health-status measures to evaluate the outcome of pulmonary rehabilitation in COPD. Respir Med 2001, 95:71-77.

21. Dolan P: Modeling valuations for EuroQol health states. Med Care 1997, 35:1095-1108

22. Hawthorne G, Richardson J, Osborne R: The Assessment of Quality of Life (AQoL) instrument: a psychometric measure of health-related quality of life. Qual Life Res 1999, 8:209-224.

23. Moore RP, Berlowitz DJ, Denehy L, Pretto JJ, Brazzale DJ, Sharpe K, Jackson B, McDonald CF: A randomised trial of domiciliary, ambulatory oxygen in patients with COPD and dyspnoea but without resting hypoxaemia. Thorax 2011, 66:32-37.

24. Ware JE, Snow KK, Kosinski M: SF-36 health survey manual and interpretation guide. Boston, MA: The Health Institute, New England Medical Center Hospitals; 1993.

25. Benzo R, Flume PA, Turner D, Tempest M: Effect of pulmonary rehabilitation on quality of life in patients with COPD: the use of SF-36 summary scores as outcomes measures. J Cardiopulm Rehabil 2000, 20:231-234.

26. Mahler DA, Mackowiak Jl: Evaluation of the short-form 36-item questionnaire to measure health-related quality of life in patients with COPD. Chest 1995, 107:1585-1589.

27. Mazur W, Kupiainen $H$, Pitkaniemi J, Kilpelainen M, Sintonen $H$, Lindqvist A Kinnula VL, Laitinen T: Comparison between the disease-specific Airways Questionnaire 20 and the generic 15D instruments in COPD. Health Qual Life Outcomes 2011, 9:4

28. Tsukino M, Nishimura K, McKenna SP, Ikeda A, Hajiro T, Zhang M, Izumi T: Change in generic and disease-specific health-related quality of life during a one-year period in patients with newly detected chronic obstructive pulmonary disease. Respiration 2002, 69:513-520

29. Janssen DJ, Wouters EF, Schols JM, Spruit MA: Self-perceived symptoms and care needs of patients with severe to very severe chronic obstructive pulmonary disease, congestive heart failure or chronic renal failure and its consequences for their closest relatives: the research protocol. BMC Palliat Care 2008, 7:5.

30. Janssen DJ, Franssen FM, Wouters EF, Schols JM, Spruit MA: Impaired health status and care dependency in patients with advanced COPD or chronic heart failure. Qual Life Res 2011, 20:1679-1688.

31. Janssen DJ, Spruit MA, Schols JM, Cox B, Nawrot TS, Curtis JR, Wouters EF: Predicting changes in preferences for life-sustaining treatment among patients with advanced chronic organ failure. Chest 2012, 141:1251-1259.

32. Janssen DJ, Spruit MA, Uszko-Lencer NH, Schols JM, Wouters EF: Symptoms, comorbidities, and health care in advanced chronic obstructive pulmonary disease or chronic heart failure. J Palliat Med 2011, 14:735-743.

33. Janssen DJ, Spruit MA, Schols JM, Wouters EF: A call for high-quality advance care planning in outpatients with severe COPD or chronic heart failure. Chest 2011, 139:1081-1088.

34. Janssen DJ, Spruit MA, Wouters EF, Schols JM: Family Caregiving in Advanced Chronic Organ Failure. J Am Med Dir Assoc 2012, 13:394-399.

35. Charlson ME, Pompei P, Ales KL, MacKenzie CR: A new method of classifying prognostic comorbidity in longitudinal studies: development and validation. J Chronic Dis 1987, 40:373-383.

36. American Thoracic Society: Standardization of Spirometry, 1994 Update. Am J Respir Crit Care Med 1995, 152:1107-1136.

37. Wilson RC, Jones PW: A comparison of the visual analogue scale and modified Borg scale for the measurement of dyspnoea during exercise. Clin Sci (Lond) 1989, 76:277-282. 
38. Zigmond AS, Snaith RP: The hospital anxiety and depression scale. Acta Psychiatr Scand 1983, 67:361-370.

39. Jones PW, Quirk FH, Baveystock CM, Littlejohns P: A self-complete measure of health status for chronic airflow limitation. The St. George's Respiratory Questionnaire. Am Rev Respir Dis 1992, 145:1321-1327.

40. Hawthorne G, Osborne R: Population norms and meaningful differences for the Assessment of Quality of Life (AQoL) measure. Aust N $Z J$ Public Health 2005, 29:136-142.

41. Kruijshaar ME, Hoeymans N, Bijl RV, Spijker J, Essink-Bot ML: Levels of disability in major depression: findings from the Netherlands Mental Health Survey and Incidence Study (NEMESIS). J Affect Disord 2003, 77:53-64.

42. Juniper E, Guyatt G, Jaeschke R: How to develop and validate a new health-related quality of life instrument. In Quality of life and pharmacoeconomics in Clinical Trials. 2 edition. Edited by Spiker B. Philadelphia: Lippincott-Raven; 1996:49-56.

43. Landis JR, Koch GG: The measurement of observer agreement for categorical data. Biometrics 1997, 33:159-174.

44. Altman DG, Bland JM: Statistics notes: the normal distribution. BMJ 1995, 310:298.

45. Katsura $\mathrm{H}$, Yamada K, Kida K: Usefulness of a linear analog scale questionnaire to measure health-related quality of life in elderly patients with chronic obstructive pulmonary disease. J Am Geriatr Soc 2003, 51:1131-1135.

46. Holland R, Smith RD, Harvey I, Swift L, Lenaghan E: Assessing quality of life in the elderly: a direct comparison of the EQ-5D and AQoL. Health Econ 2004, 13:793-805.

47. Coultas D, Frederick J, Barnett B, Singh G, Wludyka P: A randomized trial of two types of nurse-assisted home care for patients with COPD. Chest 2005, 128:2017-2024

48. Elci A, Borekci S, Ovayolu N, Elbek O: The efficacy and applicability of a pulmonary rehabilitation programme for patients with COPD in a secondary-care community hospital. Respirology 2008, 13:703-707.

49. Katsura H, Yamada K, Kida K: Both generic and disease specific healthrelated quality of life are deteriorated in patients with underweight COPD. Respir Med 2005, 99:624-630.

50. Ritva K, Pekka R, Harri S: Agreement between a generic and diseasespecific quality-of-life instrument: the $15 \mathrm{D}$ and the SGRQ in asthmatic patients. Qual Life Res 2000, 9:997-1003.

51. Pakhale S, Wood-Dauphinee S, Spahija J, Collet JP, Maltais F, Bernard S, Baltzan M, Rouleau M, Bourbeau J: Combining Both Generic and Disease-Specific Properties: Development of the McGill COPD Quality of Life Questionnaire. COPD: Journal of Chronic Obstructive Pulmonary Disease 2011, 8:255-263.

52. Barnes S, Gott M, Payne S, Parker C, Seamark D, Gariballa S, Small N: Recruiting older people into a large, community-based study of heart failure. Chronic Illn 2005, 1:321-329.

53. Steinhauser KE, Clipp EC, Hays JC, Olsen M, Arnold R, Christakis NA, Lindquist JH, Tulsky JA: Identifying, recruiting, and retaining seriously-ill patients and their caregivers in longitudinal research. Palliat Med 2006 20:745-754

54. McHorney CA, Tarlov AR: Individual-patient monitoring in clinical practice: are available health status surveys adequate? Qual Life Res 1995, 4:293-307.

55. Perneger TV: What's wrong with Bonferroni adjustments. BMJ 1998, 316:1236-1238.

doi:10.1186/1477-7525-10-98

Cite this article as: Wilke et al.: Correlations between disease-specific and generic health status questionnaires in patients with advanced COPD: a one-year observational study. Health and Quality of Life Outcomes 2012 10:98.

\section{Submit your next manuscript to BioMed Central and take full advantage of:}

- Convenient online submission

- Thorough peer review

- No space constraints or color figure charges

- Immediate publication on acceptance

- Inclusion in PubMed, CAS, Scopus and Google Scholar

- Research which is freely available for redistribution

Submit your manuscript at www.biomedcentral.com/submit
Biomed Central 